\title{
Idiopathic hypertrophic pachymeningitis mimicking prolactinoma with recurrent vision loss
}

\author{
Julie YC Lok, Nelson KF Yip, Kelvin KL Chong, CL Li, Alvin L Young *
}

\begin{abstract}
A B S T R A C T
Idiopathic hypertrophic pachymeningitis is a rare inflammatory condition with diffuse thickening of the dura mater, which may cause a compressive effect or vascular compromise. We report on a 28 -year-old Chinese woman with a history of granulomatous mastitis 7 years previously and oligomenorrhoea, headache, blurred vision, and raised prolactin level 2 years previously, that was diagnosed as prolactinoma and treated conservatively with bromocriptine. However, she had recurrent bilateral vision loss when the bromocriptine was stopped. Her symptoms were resolved by high-dose steroid injection but remained steroid-dependent. Serial magnetic resonance imaging scan showed progressive diffuse thickening of the pachymeningitis with disappearance of pituitary apoplexy. Lumbar puncture showed lymphocytosis with no organisms. Open biopsy of the meninges was performed and histology showed
\end{abstract}

features of inflammatory infiltrates and vasculitis. This is an unusual presentation of a rare condition in this age-group, with co-existing granulomatous mastitis and chronic otitis media, and is a diagnostic challenge mimicking pituitary macroadenoma and meningioma in initial magnetic resonance imaging scans.

Hong Kong Med J 2015;21:360-2
DOI: 10.12809/hkmj144295
JYC Lok, MRCSEd
NKF Yip, FCOphth
KKL Chong, FCOphth
CL Li, FCOphth
AL Young *, FCOphth
Department of Ophthalmology and Visual Sciences, The Chinese
University of Hong Kong, Prince of Wales Hospital, Shatin, Hong Kong
* Corresponding author: youngla@ha.org.hk

\section{Introduction}

Idiopathic hypertrophic pachymeningitis is a rare inflammatory condition characterised by fibrosis and thickening of the dura mater. Diagnosis of idiopathic hypertrophic pachymeningitis requires a high index of suspicion, as its initial manifestation could be subtle clinically and radiologically. Idiopathic hypertrophic pachymeningitis has posed considerable diagnostic challenges to attending clinicians, including radiologists, neurologists, and ophthalmologists because of its highly variable presentation. Apart from clinical subtlety and variability, idiopathic hypertrophic pachymeningitis is also a great imposter because it can mimic other common and important neurological conditions such as prolactinoma.

\section{Case report}

A 28-year-old Chinese woman with a history of granulomatous mastitis 7 years previously was noted to have oligomenorrhoea, nausea, headache, and raised prolactin level of $1261.0 \mathrm{mIU} / \mathrm{L}$ (reference range [RR], 108.8-557.1 mIU/L) since March 2011. Her baseline hormone profile was otherwise normal. Plain magnetic resonance imaging (MRI) scan showed an enlarged pituitary gland of up to $1.6 \mathrm{~cm}$
(Figs 1a and 1b). At that time she was diagnosed with prolactinoma and treated with bromocriptine; her prolactin level was well-controlled subsequently.

After cessation of bromocriptine at the end of 2012, she developed periodic headache and flickering vision loss since May 2013. Her bestcorrected visual acuities were $20 / 40$ and 20/30 in her right and left eyes, respectively. She developed red colour desaturation of around 30\%. Humphrey visual field 30-2 test showed superior field loss in the right eye, while the left eye was full field loss. Six weeks later her visual acuity decreased to $20 / 800$ in the right eye and 20/400 in the left eye. She was given dexamethasone and her visual acuity increased to $20 / 20$ and 20/16 in the right and left eyes, respectively. Other slit-lamp and fundal examinations were unremarkable. There was no papilloedema. There was no involvement of other cranial nerves. Glasgow Coma Scale score was 15/15 throughout. Magnetic resonance imaging with contrast showed increased contrast enhancement and inflammation over the dura of the sella and cavernous sinus (Figs $1 \mathrm{c}$ and 1d). Her symptoms resolved and visual function recovered quickly with high-dose steroid. However, she developed steroid dependency since repeated attacks developed when the steroid was stopped. 
Serial MRI scan showed progressive diffuse thickening of the pachymeningitis with disappearance of pituitary apoplexy, together with chronic otitis media (Figs 1c and 1d). Lumbar puncture showed $13 \mathrm{~cm} \mathrm{H}_{2} \mathrm{O}$ and lymphocytosis without organisms. Open biopsy of the meninges was performed and histology showed features of inflammatory infiltrates and vasculitis, but was negative for malignancy (Fig 2 ). Gene rearrangement polymerase chain reaction assay for immunoglobulin (Ig) heavy chain, T-cell receptor (TCR)-beta and TCR-gamma all showed no clonal peak. Polymerase chain reaction for Mycobacterium tuberculosis and culture for dural biopsy were also negative; IgG4 was $975 \mathrm{mg} / \mathrm{L}$ (RR, 61-1214 mg/L). Complete blood count showed normal haemoglobin, white blood cell, and platelet levels. Liver and renal function tests, serum calcium, creatine kinase, and lactate dehydrogenase levels were normal. Erythrocyte sedimentation rate was raised to $113 \mathrm{~mm} / \mathrm{h}$ ( $\mathrm{RR}, 0-20 \mathrm{~mm} / \mathrm{h}$ ). C-reactive protein was raised at $67.4 \mathrm{mg} / \mathrm{L}$ (reference level, $<9.9 \mathrm{mg} / \mathrm{L}$ ). In coagulation profile, activated partial thromboplastin time was slightly prolonged to 40.0 seconds (RR, 28.2-37.4 seconds). Autoimmune markers, including anti-nuclear antibodies, antineutrophil cytoplasmic antibodies, anti-DNA immunofluorescence test, anti-extractable nuclear antigen, anti-cardiolipin antibodies, and rheumatoid factors are all negative except for the presence of lupus anticoagulant. Complement C3 was normal while complement $\mathrm{C} 4$ was slightly raised to $0.42 \mathrm{~g} / \mathrm{L}$ (RR, 0.1-0.4 g/L). Serum vitamin B12 level was $552 \mathrm{pmol} / \mathrm{L}(\mathrm{RR}, 156-698 \mathrm{pmol} / \mathrm{L})$ and serum folate level was $29.3 \mathrm{nmol} / \mathrm{L}$ ( $\mathrm{RR}, 10.4-42.4 \mathrm{nmol} / \mathrm{L}$ ); IgG4 was 975 mg/L. Virology screening-including human immunodeficiency virus, hepatitis B virus, and hepatitis $C$ virus-was negative. Serum and cerebrospinal fluid Venereal Disease Research Laboratory tests were negative. Chest X-ray was clear with no features of tuberculosis or sarcoidosis.

The patient was initially treated with pulse steroid and was well-controlled by low-dose steroid. She remained symptom-free 6 months after biopsy.

\section{Discussion}

Idiopathic hypertrophic pachymeningitis is a rare inflammatory condition involving focal and/or diffuse thickening and fibrosis of the dura mater. Thickened dura mater with local mass effect may be pathognomonic of this condition. This pressure effect may serve as a mechanistic explanation of the observed neurological defect. As almost every part of the dura mater can be affected focally and/or diffusely, there is a highly variable clinical picture. ${ }^{1,2}$ Diagnosis is almost always made by exclusion of a large number of aetiologies, for example, infectious causes such as Lyme disease, syphilis, and $M$ tuberculosis; inflammatory causes such as Wegener

\section{特發性肥厚性硬腦膜炎疑似泌乳素瘤復發性} 視力減退

\author{
駱映晴、葉國富、莊金隆、李熾禮、楊樂旼
}

特發性肥厚性硬腦膜炎是一種罕見的炎性疾病, 其特點是硬腦膜的濔 散性增厚, 使腦神經受壓或影響血流。本文報告一名28歲華籍女性, 她七年前曾患有肉芽腫性乳腺炎, 兩年前出現月經稀發、頭痛、視力 模糊和催乳素水平升高; 當時被診斷為泌乳素瘤, 遂接受溴隱亭的保 守療法。患者停止服用溴隱亭後出現復發性雙側視力減退。經大劑量 的類固醇注射後症狀消失; 類固醇治療雖然有效, 但會形成依賴。連 續的磁共振成像掃描顯示患者有進行性濔漫性增厚的硬腦膜炎, 垂體 中風消失。腰椎穿刺檢查顯示淋巴細胞增多但未有發現細菌。腦膜開 放性切除活組織檢查顯示有炎性浸潤和血管炎。這病例對於同年齡組 別的病人來説很罕見。患者同時有肉芽腫性乳腺炎和慢性中耳炎。由 於其磁共振影像與垂體大腺瘤和覤底底膜瘤很相似, 會造成診斷上的 一大挑戰。

granulomatosis, $^{3}$ rheumatoid arthritis, Behçet disease, and sarcoidosis (which is rare in Chinese people); and malignancy. In this patient, these tests were all negative, so the diagnosis of idiopathic hypertrophic pachymeningitis was made.
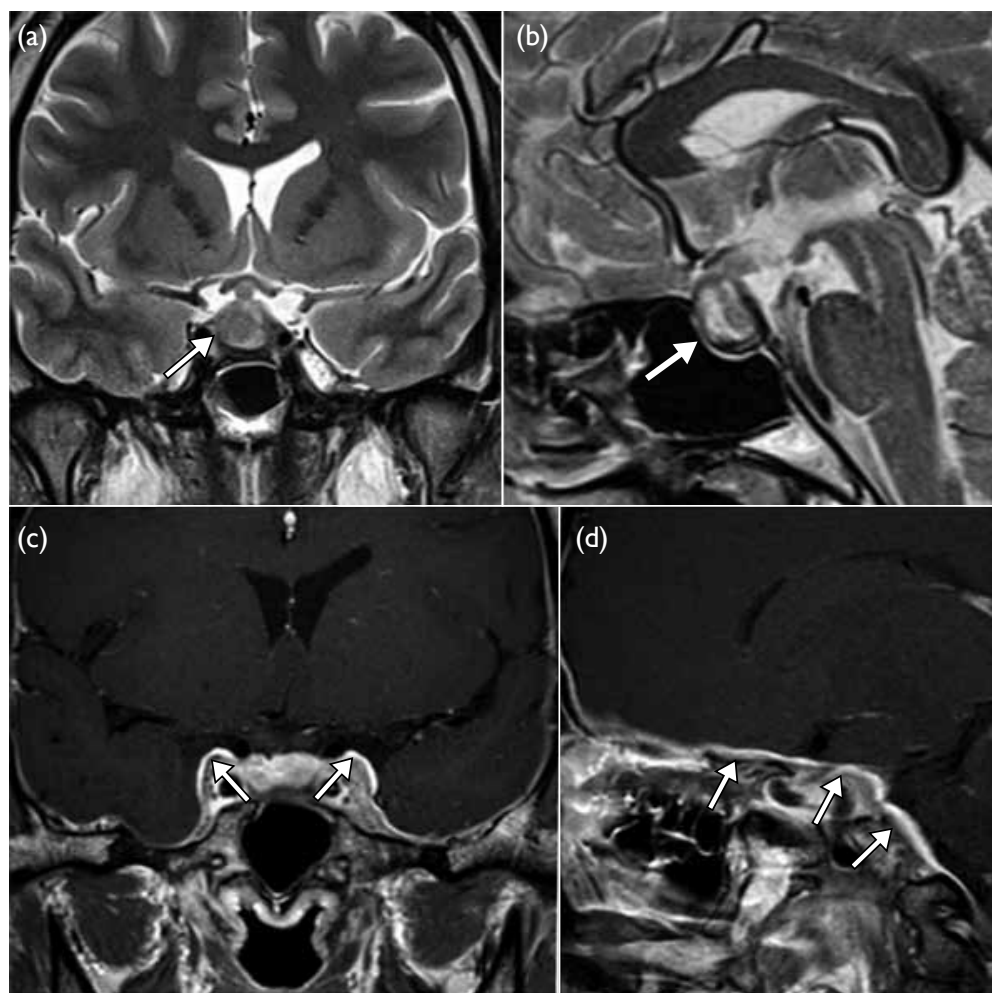

FIG I. Magnetic resonance images showing generalised increased pachymeningeal enhancement in the bilateral frontal-parietal-temporal regions just before steroid treatment in June 2013

Non-contrast (a) coronal and (b) sagittal scans showing an enlarged pituitary gland of up to $1.6 \mathrm{~cm}$ with optic compression and central necrosis (arrows); contrast (c) coronal and (d) sagittal scans showing diffuse pachymeningeal thickening and enhancement over cavernous sinus, clivus, skull base extended into orbit (arrows) 


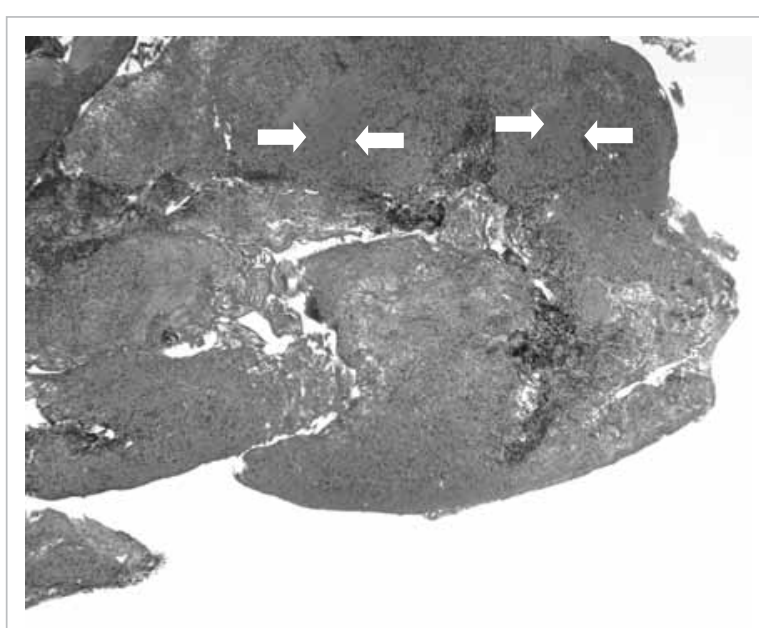

FIG 2. Histology slide showing inflammatory changes as vasculitis (arrows) and negative for malignancy (H\&E; original magnification, $\times$ 10)

Demographically, the median age of patients with idiopathic hypertrophic pachymeningitis is 58.3 years (standard deviation, 15.8; range, 37-88 years). ${ }^{4-6}$ Only a few paediatric patients have been reported, with the youngest age being 2 years and 11 months in India. ${ }^{7}$ Our patient had early-onset disease. There are few data on ethnicity due to the rarity of the disease. Idiopathic hypertrophic pachymeningitis is extremely rare in Chinese people.

The exact aetiopathophysiology of idiopathic hypertrophic pachymeningitis is not known. It is believed to be autoimmune in origin. ${ }^{8}$ Lupus anticoagulant is a type of autoantibody that binds to phospholipid and protein, which is commonly associated with autoimmune diseases such as systemic lupus erythematous and antiphospholipid syndrome. ${ }^{9}$ Our patient's symptoms and signs did not fit into any diagnostic category of autoimmune disease. Only the presence of lupus coagulants might suggest that idiopathic hypertrophic pachymeningitis is a form of vasculitis, which might share some common phenomenon with other autoimmune diseases, although the true relationship is controversial.

Clinically, headache is by far the most common feature and the optic nerve is one of the most common cranial nerves to be involved, which was the case for this patient. Multiple cranial nerve involvement, ataxia, cortical blindness, psychosis, motor function disturbance, fever, convulsion, and/or loss of consciousness have all been reported.5,6 Yamada et $\mathrm{al}^{2}$ thought that the inflammatory thickening of the dura may cause damage to the superior hypophyseal artery resulting in subarachnoid haemorrhage and apoplexy in the anterior lobe of the pituitary gland.
The posterior lobe was spared in their patient, who had a normal hormonal profile, unlike our patient. The initial enlarged pituitary gland with raised prolactin was more likely to result from the stalk effect than from true prolactinoma.

Granulomatous mastitis is a rare idiopathic chronic benign breast condition, which is believed to be autoimmune in origin, and mainly affects women of child-bearing age. ${ }^{10}$ Granulomatous mastitis is mainly diagnosed by exclusion of other diagnoses. To the best of our knowledge, this is the first case of idiopathic hypertrophic pachymeningitis reported with the association of granulomatous mastitis, possibly related to the scarcity of cases affecting menstruating women.

Idiopathic hypertrophic pachymeningitis is a rare condition with a highly variable clinical presentation making accurate and timely diagnosis difficult. Therefore the attending clinician should maintain high vigilance in the event of an atypical presentation of a presumably typical disease. Early diagnosis and prompt therapeutic intervention such as high-dose steroid may be the key to preserving vision as well as life.

\section{References}

1. Christakis PG, Machado DG, Fattahi P. Idiopathic hypertrophic pachymeningitis mimicking neurosarcoidosis. Clin Neurol Neurosurg 2012;114:176-8.

2. Yamada SM, Aoki M, Nakane M, Nakayama H. A case of subarachnoid hemorrhage with pituitary apoplexy caused by idiopathic hypertrophic pachymeningitis. Neurol Sci 2011;32:455-9.

3. Yokoseki A, Saji E, Arakawa M, et al. Hypertrophic pachymeningitis: significance of myeloperoxidase antineutrophil cytoplasmic antibody. Brain 2014;137:520-36.

4. Yonekawa $\mathrm{T}$, Murai $\mathrm{H}$, Utsuki $\mathrm{S}$, et al. A nationwide survey of hypertrophic pachymeningitis in Japan. J Neurol Neurosurg Psychiatry 2014;85:732-9.

5. Riku S, Kato S. Idiopathic hypertrophic pachymeningitis. Neuropathology 2003;23:335-44.

6. Kupersmith MJ, Martin V, Heller G, Shah A, Mitnick HJ. Idiopathic hypertrophic pachymeningitis. Neurology 2004;62:686-94.

7. Sharma PK, Saikia B, Sharma R, Gagneja V, Khilnani P. Pachymeningitis in a young child responded to antitubercular therapy: a case report. J Child Neurol 2014;29:NP92-5.

8. Masson C, Boukriche Y, Colombani JM. Inflammatory hypertrophic cranial pachymeningitis. Presse Med 2001;95:65-70.

9. Favaloro EJ, Wong RC. Antiphospholipid antibody testing for the antiphospholipid syndrome: a comprehensive practical review including a synopsis of challenges and recent guidelines. Pathology 2014;46:481-95.

10. Poovamma CU, Pais VA, Dolas SC, Prema M, Khandelwal R, Nisheena R. Idiopathic granulomatous mastitis: a rare entity with a variable presentation. Breast Dis 2014;34:1014. 